Décadrages Décadrages

cinéma, à travers champs Cinéma, à travers champs

$7 \mid 2006$

Stephen Dwoskin

\title{
Exit ou la fuite du point de vue
}

\section{Marthe Porret}

\section{OpenEdition}

Journals

Édition électronique

URL : https://journals.openedition.org/decadrages/461

DOI : $10.4000 /$ decadrages.461

ISSN : 2297-5977

\section{Éditeur}

Association Décadrages

\section{Édition imprimée}

Date de publication : 10 avril 2006

Pagination : 105-107

ISBN : 978-29700582-3-6

ISSN : 2235-7823

Référence électronique

Marthe Porret, «Exit ou la fuite du point de vue », Décadrages [En ligne], 7 | 2006, mis en ligne le 30 janvier 2014, consulté le 03 avril 2022. URL : http://journals.openedition.org/decadrages/461 ; DOI https://doi.org/10.4000/decadrages.461

Ce document a été généré automatiquement le 3 avril 2022.

(B) Décadrages 


\title{
Exit ou la fuite du point de vue
}

\author{
Marthe Porret
}

1 Une des questions récurrentes - en tout cas celle qu'en tant que spectatrice je me pose d'emblée devant n'importe quel film - est de savoir quel degré d'adhésion il existe entre le réalisateur et son sujet ; entre le contenu et celui qui nous le livre, au final, sur l'écran. Au vu des échos que le documentaire de Fernand Melgar a engendrés dans la presse $^{1}$, il semble que l'on ne se soit jamais posé la question, ou plutôt qu'il soit admis sans discussion que si Melgar a choisi de filmer les activités de l'association Exit, c'est qu'il ne remet pas en cause son existence. Que le sujet soit «bouleversant $»^{2}$, certes cela va de soi, encore qu'il serait plus juste de dire que le film pose des questions fondamentales et nécessaires. C'est là que réside son principal intérêt. Mais que nous soyons tous, réalisateur compris, bouleversés, c'est une autre chose. Je rejoins ici l'appel à la "lucidité critique et à la résistance éthique ${ }^{3}$ lancé par Denis Müller et Marco Vannotti, qui dénoncent avec justesse l'imposture d'une association fière d'offrir clé en main une mort « confortable $»^{4}$.

2 Je veux croire cependant que le cinéaste ne cautionne pas totalement et sans réserve Exit. J'en veux pour preuve que son documentaire, comme tout documentaire, n'est pas la relation brute et accidentelle d'une réalité, mais son traitement discursif par le biais d'une mise en scène et d'un montage particuliers. La séquence du pré-générique en offre un premier exemple. En off puis à l'image, des appels téléphoniques sont montés les uns à la suite des autres de sorte que leur accumulation devient surréalisante : la dépressive, le parapentiste qui a peur de s'estropier, la femme atteinte de sclérose en plaques, etc. Le tout-venant de la détresse humaine frappe à la porte d'Exit dans une volonté d'abréger ses souffrances, certains sans être par ailleurs dans un stade terminal. Le film de Melgar est très intéressant à cet égard, dans la mesure où il ne fait que montrer des personnes qui, fuyant toute responsabilité - «Que me proposez-vous de mieux ? » demande une jeune femme invalide - n'assument pas eux-mêmes le geste qui mettrait fin à leur existence et qui représenterait en cela la liberté suprême de chaque individu. Accompagnateurs comme patients n'utilisent d'ailleurs jamais le terme de « suicide », mais celui d' « autodélivrance ». 
3 Autre exemple, frappant tout au long du film par ailleurs: la caméra et le micro s'immiscent dans les conversations d'autrui sans que personne ne semble remarquer leur présence. Lors d'une assemblée générale, ne réunissant visiblement que des retraités privilégiés et des handicapés, la caméra ne cesse de filmer des visages remplis d'autosatisfaction; la discussion assez intime durant l'apéritif qui suit entre une veuve et un veuf est littéralement filmée dans leur dos, tandis que le micro "vole» complaisamment anecdotes et lieux communs. Le ridicule n'est jamais loin. Mais on peut avancer a contrario que si la caméra, invisible, s'efface devant son sujet, c'est qu'entre filmeur et filmé règne une confiance absolue. Notre constat est donc à double tranchant!

Troisième exemple, enfin, qui démontre de façon éclatante la contradiction absolue que l'association Exit cache et qui s'exprime au cours d'un bloc narratif monté dans son intégralité : une femme commence par dire «qu'elle a pété les plombs ». A la question de savoir si elle a déjà tenté de se suicider, ce qu'elle confirme, la standardiste d'Exit précise que les demandes émanant de personnes atteintes psychiquement ne sont pas prises en compte. La femme s'empresse de préciser qu'elle a la sclérose en plaques. La standardiste lui confirme alors que le formulaire ad hoc va lui être envoyé !

Un dernier exemple, ambigu là encore : la réunion des douze bénévoles autour du $\mathrm{Dr}$ Sobel, séquence au sujet de laquelle beaucoup de critiques ont évoqué - à juste titre une Sainte Cène. Si l'on peut en effet facilement convenir que le réalisateur n'a pas ici sciemment mis en scène les membres d'Exit qui, soit dit en passant, se montrent très conscients de leurs faits et gestes face aux patients et à la caméra, il est évident que Melgar renforce de son côté l'analogie picturale aux Evangiles en cadrant de façon frontale et à hauteur d'homme. La connotation christique est d'autant plus évidente qu'on a pu lire dans la presse que «selon le cinéaste, les accompagnateurs d'Exit sont des espèces de pionniers, d'apôtres, qui réinventent le sacré, le spirituel $»^{5} \ldots$ S'ils réinventent le sacré, c'est d'une façon malheureusement si réductrice et si vague (métaphore de la lumière, du grand voyage) qu'on ne peut être frappé que d'une chose : on ne s'improvise pas prêtre!

6 Cette absence de point de vue ne serait pas si problématique si le sujet choisi n'était pas si grave. Il est par ailleurs dommage que le cinéaste n'ait pas cherché à sonder le vide juridique que représente l'article 115 du Code pénal suisse qui stipule, grosso modo, que l'assistance au suicide est punissable uniquement dans le cas de motivations égoïstes. Toute personne dénuée de tels motifs peut donc prêter main-forte à qui veut en finir, sans encourir de condamnation. Les motivations du Dr Sobel et de son équipe de bénévoles sont-elles totalement pures et dénuées d'amour-propre? On a de la peine à le croire, surtout lorsqu'un membre de l'association arbore fièrement une médaille récompensant son zèle d'accompagnateur. Reste que le film, il faut le souligner, en s'attelant au tabou de filmer la mort en direct, ne sombre jamais dans l'impudeur. Et en alertant l'opinion publique au sujet d'un phénomène de société inquiétant, il s'avère malgré tout nécessaire.

Exit - le droit de mourir (2005). Réal. et scénario : Fernand Melgar. Image : Camille Cottagnoud, Steff Bossert. Montage : Karine Sudan. Son : Blaise Gabioud, Philippe Jacquet, Denis Sechaud. Production : Climage, Fernand Melgar (Lausanne), Les Productions JMH, Florence Adam (Neuchâtel). 


\section{NOTES}

1. Je pense par exemple à l'article d'Antoine Duplan paru dans L'Hebdo du 1.09.05, article qui lui a valu le Prix Pathé - Prix de la critique de cinéma 2006 à Soleure.

2. Antoine Duplan, op. cit.

3. Le Temps, 7.12.2005.

4. Ce sont les mots d'une des accompagnatrices qui évoque les difficultés que le patient peut rencontrer à déglutir correctement le poison.

5. Antoine Duplan, op. cit. 